\title{
Modulation of tactile duration judgments by emotional pictures
}

\author{
Zhuanghua Shi ${ }^{1}{ }^{*}$, Lina Jia ${ }^{1}$ and Hermann J. Müller ${ }^{1,2}$ \\ Department of Psychology, Experimental Psychology, Ludwig-Maximilians-Universität München, Munich, Germany \\ 2 School of Psychological Science, Birkbeck College (University of London), London, UK
}

\author{
Edited by: \\ Micah M. Murray, Université \\ de Lausanne, Switzerland \\ Reviewed by: \\ Hao Zhang, Purdue University, USA \\ Domenica Bueti, Centre Hospitalier \\ Universitaire Vaudois and University \\ of Lausanne, Switzerland \\ *Correspondence: \\ Zhuanghua Shi, Department of \\ Psychology, Experimental \\ Psychology, \\ Ludwig-Maximilians-Universität \\ München, 80802 Munich, Germany. \\ e-mail: shi@psy.Imu.de
}

Judging the duration of emotional stimuli is known to be influenced by their valence and arousal values. However, whether and how perceiving emotion in one modality affects time perception in another modality is still unclear. To investigate this, we compared the influence of different types of emotional pictures-a picture of threat, disgust, or a neutral picture presented at the start of a trial—on temporal bisection judgments of the duration of a subsequently presented vibrotactile stimulus. We found an overestimation of tactile duration following exposure to pictures of threat, but not pictures of disgust (even though these scored equally high on arousal), in a short-range temporal bisection task (range $300 / 900 \mathrm{~ms}$ ). Follow-up experiments revealed that this duration lengthening effect was abolished when the range to be bisected was increased (1000/1900 ms). However, duration overestimation was maintained in the short-range bisection task regardless of whether the interval between the visual and tactile events was short or long. This pattern is inconsistent with a general arousal interpretation of duration distortion and suggests that crossmodal linkages in the processing of emotions and emotional regulation are two main factors underlying the manifestation of crossmodal duration modulation.

Keywords: duration estimation, emotion, threat, visual-tactile interaction, embodiment

\section{INTRODUCTION}

Judgments of time intervals are often distorted by the emotional state a person is in. For instance, when involved in an accident, such as car crash, people often report that they felt the world slow down. Although the phenomenon has been known for long, it has only been sparsely examined (Lang et al., 1961; Hare, 1963), with more systematic studies published only in recent years (Angrilli et al., 1997; Droit-Volet et al., 2004; Droit-Volet and Gil, 2009).

The most simple and classical explanation of interval timing is provided by the internal clock model (Treisman, 1963; Gibbon et al., 1984; Zakay and Block, 1996). This model assumes an internal pacemaker that emits pulses at regular intervals, and a switch that starts and stops the counting of pulses. The pulses recorded by an accumulator represent the subjective time. Studies on emotion and time have shown that emotion can influence the internal pacemaker and/or the switch and strongly distort perceived duration (see review Droit-Volet et al., 2004). For example, Angrilli and colleagues examined duration estimation for emotional pictures, taken from the international affective picture system (IAPS) (Lang et al., 2005), presented for 2, 4, or $6 \mathrm{~s}$. They found that both emotional valence and arousal were important factors in duration judgments. For high-arousal stimuli, negative pictures (e.g., mutilated bodies) were perceived as longer in duration compared to positive pictures (e.g., erotic scenes). In contrast, for lowarousal stimuli, duration of negative pictures was judged shorter than that of positive pictures (Angrilli et al., 1997). Angrilli et al. argued that two different mechanisms, one attentional and the other emotional, play important roles in time judgment. Negative events themselves engage more attentional resources (as also indicated by lowered heart rates). As a result, less attention is devoted to time processing and the negative events' durations tend to be underestimated. For high-arousal stimuli, so they argued, the effect of attention is minimized, and an emotional mechanism triggered by the pictures dominates the time estimation. Since high-arousal negative pictures evoke a defense response (Bradley et al., 2001), the duration of negative pictures is overestimated. By contrast, positive pictures evoke an approach response and thus their durations are underestimated. Similarly, other studies have shown that angry faces were judged as longer than neutral faces (Droit-Volet et al., 2004; Droit-Volet and Meck, 2007). It has been argued that both anger and fear are arousing emotions (Phelps and LeDoux, 2005), which increase the internal pacemaker rates, leading to temporal overestimation. Besides the visual modality, emotional modulation of time perception has also been found in the auditory modality (Noulhiane et al., 2007). Emotional sounds (e.g., a woman crying) were often judged as longer than neutral ones; and negative sounds were perceived as longer than positive ones (e.g., laughs).

Although there is now ample evidence of how emotion distorts duration perception, most of the studies have focused on unisensory modulation only. Given this, to date, there is still only scant understanding of how emotion-induced from one sensory modality influences time judgments in another modality. The likely reason is that emotional effects are generally (and tacitly) assumed to be amodal in nature i.e., emotional arousal or anxiety exerts a general influence, not restricted to one sensory modality. 
This implicit assumption can be clearly seen in early crossmodal duration studies. For example, Hare attempted to examine how electrical shock influences auditory interval judgments (Hare, 1963). Auditory intervals were defined by two successive clicks. In the shock condition, a moderately painful (tactile) shock was delivered to participants' fingers at the second click, to induce general anxiety. Hare found that anxiety did indeed lead to a greater overestimation of auditory intervals compared to the baseline condition. However, recent crossmodal studies have provided evidence that each sensory system may possess its own clock (see review Bueti, 2011) and time processing is distributed across brain regions (Matell and Meck, 2004). The sensory-specific clock model is supported by behavioral evidence, such as for modalityspecific pacemaker rates (Wearden et al., 1998; Penney et al., 2000; Droit-Volet et al., 2007), as well as by neurophysiological evidence, for example, for separate brain regions underlying visual and auditory duration processing (Ghose and Maunsell, 2002; Bueti et al., 2008; Bueti, 2011). Studies on non-emotional crossmodal duration judgments have revealed rather complex and inconclusive results (Walker and Scott, 1981; van Wassenhove et al., 2008; Chen and Yeh, 2009; Chen et al., 2010, 2011; Shi et al., 2010). For example, van Wassenhove et al. (2008) examined influences of visual (and, respectively, auditory) inputs on duration judgments of auditory (visual) events using looming and receding stimuli. They found the duration of auditory events was lengthened or shortened by the presence of conflicting visual information, while the perceived duration of visual events was unaffected by auditory stimuli. However, other studies using static stimuli or implicit measures have reported the opposite effect, i.e., perceived visual duration was affected by auditory duration (Chen and Yeh, 2009; Shi et al., 2010). Interestingly, in order to explain the crossmodal duration interaction by looming stimuli, van Wassenhove et al. (2008) suggested that salient, looming stimuli might be treated as "threat" signals (i.e., as having a negative emotional valence), causing duration dilation within and across modalities. Again, as concerns emotion, the influence of emotion on duration judgments was implicitly assumed to reflect a sense-independent arousal effect.

However, as suggested by recent discrete emotion theory (Izard and Ackerman, 2000; Mikels et al., 2005), the arousal and valence dimensions may not provide a complete description of emotions. It is also conceivable that different types of emotion link to different behavioral functions and sensory modalities. For example, although both threat and disgust are categorized as high-arousal negative-valence emotions, they activate different processes. Threat activates our defensive system and biases motor responses (Bradley et al., 2001). Given that a threatening or dangerous event is most likely directed toward our body (e.g., the sight of a snake attacking), an association between what we see and what we feel in our body can be quickly established (Poliakoff et al., 2007). This, in turn, may increase the tactile pacemaker speed and/or shorten the latency of the switch. Disgust, by contrast, is more related to avoiding something detrimental to our health or something tasting bad (Rozin and Fallon, 1987; DroitVolet and Gil, 2009). Given this, the linkage between the visual and the tactile system by disgust events might not be as strong as that by threat events. Consequently, visual disgust signals may have only a relatively weak, if any, influence on the internal clock of the tactile system.

Moreover, duration judgments may also be influenced by the strength of perception-action associations. Research on duration estimation of emotional faces has shown that angry or fearful faces are often perceived as longer than neutral faces (Droit-Volet et al., 2004; Effron et al., 2006). However, when participants in such a study held a pen in their mouth to inhibit imitation of emotional faces, the duration lengthening was abolished (Effron et al., 2006). This finding suggests that perception-action associations are one of the critical factors causing changes of the internal clock system. Crossmodal associations induced by emotional stimuli might have a similar impact on time judgments.

To examine whether crossmodal emotional modulation of perceived duration is a general arousal effect or an emotion-specific effect, we compared modulations induced by three types of emotional pictures (threat, disgust, and neutral) on subsequent judgments of vibrotactile duration (Experiment 1). We chose threat and disgust since both are categorized as high-arousal negative emotions. If crossmodal emotional modulation reflected a general arousal effect, both types of emotional picture would engender similar distortions of tactile duration judgments. On the other hand, images depicting threat or fear may have particularly strong associations with the defensive system, compared to disgusting images. As supported by studies on affective modulation of the human startle blink (Balaban and Taussig, 1994; Stanley and Knight, 2004), blink magnitude was significantly larger during the presentation of frightening pictures compared to disgusting pictures. Thus, an alternative prediction is that threatening pictures would influence perceived duration by related sensory systems, such as touch, more than disgusting pictures would.

To further investigate the mechanisms underlying crossmodal emotional modulation of the internal clock system, we explored effects of emotions by comparing their modulatory influences between short and long tactile durations (Experiment 2) as well as short and long inter-stimulus intervals (ISIs) between the emotional picture and the vibrotactile stimulus (Experiment 3). Analogous to unimodal studies, the rationale was to examine whether the internal pacemaker rate or/and the switch latency in the tactile modality are changed by emotional events from visual modality. If the tactile pacemaker rate is impacted, one would expect a slope effect (multiplicative effect) on short and long duration judgments (Wearden, 1992, 2006), i.e., the crossmodal emotional influence should be greater for long than for short durations. By contrast, if emotion influences only the switch latency, one would expect duration overestimation for both short and long duration conditions. However, if processes of emotional regulation supersede processes of activation during a late stage of processing, one might fail to observe duration overestimation in the long duration condition. Experiments 2 and 3 were designed to examine for these effect patterns.

\section{MATERIALS AND METHODS PARTICIPANTS}

Fourteen (six female; mean age 28), 15 (10 female; mean age 25 ), and 16 volunteers (10 female; mean age 25 ) took part in Experiments 1, 2, and 3, respectively. All participants had 
normal or corrected-to-normal vision, and none reported any somatosensory disorder. Written informed consent was obtained before the experiments.

\section{MATERIALS}

The experiments took place in a sound-isolated cabin, which was dimly lit with an ambient luminance of $0.76 \mathrm{~cd} / \mathrm{m}^{2}$. Visual stimuli were presented on a 21 inch Sony CRT monitor with a refresh rate of $100 \mathrm{~Hz}$. The viewing distance was kept constant at $57 \mathrm{~cm}$ using a chin-rest. Tactile vibration $(250 \mathrm{~Hz})$ was produced by an AEC TACTAID VBW32 vibrator (Audiological Engineering Corporation; Vibrating surface $1.6 \times 2.4 \mathrm{~cm}$ ), which was fixed to the index finger of the participant's right hand. The participant was asked to place her/his right hand, behind a short black curtain, on the table in front of her/him; the curtain ensured that the participant could not see her/his hand, while she/he had a free view of the display screen. Visual and tactile stimuli presentation was controlled by a Matlab program using the Psychophysics Toolbox (Brainard, 1997).

Three types of pictures were selected from the IAPS (Lang et al., 2005): threatening pictures evoking high-arousal (such as a snake, shark, etc.); disgusting pictures also classed as high on arousal (such as a burn victim, mutilation); and neutral pictures rated "neutral" in both valence and arousal. For Experiment 1, we used five pictures of disgust (mean valence 1.69; mean arousal 6.90 ), five pictures of threat (mean valence 3.28 ; mean arousal 6.73 ), and 10 neutral pictures (mean valence 4.82 ; mean arousal 2.47). For Experiments 2 and 3, we selected 10 threatening and 20 neutral pictures. Pictures were then evenly divided into two groups, each containing five attacking (mean valence 3.3; mean arousal 6.7) and 10 neutral pictures (mean valence 4.9 ; mean arousal 2.7); these were assigned randomly to one or the other of two test sessions (see details in Procedure section). Descriptions and IAPS numbers of the pictures are given in Table A1.

\section{PROCEDURE}

We used a temporal bisection task in all experiments. Participants were first trained with two anchor tactile durations: a short vibration (S) and a long vibration (L). Then, in the subsequent test sessions, several probe durations between $\mathrm{S}$ and $\mathrm{L}$ were presented to participants, who had to indicate whether the probe duration was closer to S or to L. In Experiments 1 and 3, S and L durations were 300 and $900 \mathrm{~ms}$ and the probe durations were 400, 500, 600, 700, and $800 \mathrm{~ms}$, respectively. In Experiment 2, there were two different ranges of temporal bisection tasks: $300 / 900 \mathrm{~ms}$ and $1000 / 1900 \mathrm{~ms}$. For the range of $300 / 900 \mathrm{~ms}, \mathrm{~S}, \mathrm{~L}$, and probe durations were the same as in Experiment 1. For the range of $1000 / 1900 \mathrm{~ms}$, S and L durations were 1000 and $1900 \mathrm{~ms}$ and the probe durations were $1150,1300,1450,1600$, and $1750 \mathrm{~ms}$, respectively.

In the training session, an experimenter sat beside the participant to make sure that her/his anchor discrimination performance reached perfect level. Then, the experimenter left the cabin and the test session started. In the test session, a trial started with a "go" display which contained a central blue fixation dot (subtending $0.3^{\circ}$ of visual angle) and the blue word "Ready!" just above fixation on a gray background. After the participant pressed a button, the "go" display disappeared and a blank display was shown randomly for 300-800 ms. Then a picture, randomly chosen from selected pictures, was presented for $1 \mathrm{~s}$. In Experiments 1 and 2, after a short, random ISI of 400-600 ms, a vibration was delivered to the participant's index finger for a given probe duration (see above). In Experiment 3, the ISIs between picture and vibration were fixed to be either short ( $500 \mathrm{~ms}$ ) or long (1500 ms). When the vibration had terminated, a question mark was displayed on the screen prompting the participant for a response: she/he had to judge, as accurately as possible, whether the duration of the vibration was closer to $\mathrm{S}$ or to $\mathrm{L}$ and indicate the choice by pressing keys labeled "short" and "long" on the keyboard. The inter-trial interval (ITI) was set to $4-6 \mathrm{~s}$, in order to avoid potential inter-trial interference. There were four blocks, each of 25 trials. At the beginning of each block, both the $\mathrm{S}$ and $\mathrm{L}$ anchor durations were presented five times each, for refreshing the participant's memory of two anchors. Participants took rests of about 1 min between blocks.

After the test session, the participant was asked to rate the valence and arousal of the pictures using a sheet of paper with 9point scales self-assessment-manikin (SAM) (Bradley and Lang, 1994).

\section{RESULTS}

\section{ASSESSMENT OF EMOTIONS}

For Experiment 1, a repeated-measures ANOVA revealed rated valence to differ significantly among threatening, disgusting, and neutral pictures, $\left[F_{(2,26)}=94.08, p<0.01\right]$. Follow-up Bonferroni $t$-tests showed that the average valence was lower for disgusting pictures compared to both threatening and neutral pictures (both $p<0.01$ ), and the mean valence of threatening pictures was lower than that of neutral pictures, $p<0.01$. A further repeated-measure ANOVA revealed rated arousal, too, to differ significantly among conditions, $\left[F_{(2,26)}=112.89, p<\right.$ $0.01]$. Follow-up Bonferroni $t$-tests showed that disgusting and threatening pictures were higher in arousal ratings than neutral pictures (both $p<0.01$ ), whithout a difference between the former $(p>0.1)$.

The mean valence of threatening pictures was significantly lower than that of neutral pictures, in both Experiment 2 $\left[F_{(1,14)}=77.79, p<0.01\right]$ and Experiment $3\left[F_{(1,15)}=116.94\right.$, $p<0.01]$. Furthermore, repeated-measures ANOVAs revealed the mean arousal to be significantly higher for threatening than for neutral pictures, $\left[F_{(1,14)}=86.30, p<0.01\right]$ (Experiment 2$)$ and $\left[F_{(1,15)}=125.88, p<0.01\right]$ (Experiment 3$)$.

Thus, the results of the subjective ratings were consistent with the rating of valence and arousal from the IAPS.

\section{TEMPORAL BISECTION}

The proportions of "long" responses were calculated for the five probe durations and fitted by a logistic function, for each condition and each subject. The temporal bisection point (TBP) was then calculated based on the $50 \%$ point of a given estimated logistic function (Treutwein and Strasburger, 1999). To measure the sensitivity of the temporal bisection task, we estimated the just noticeable difference (JND) of the temporal bisection using the half difference in duration between the $25 \%$ and $75 \%$ point 


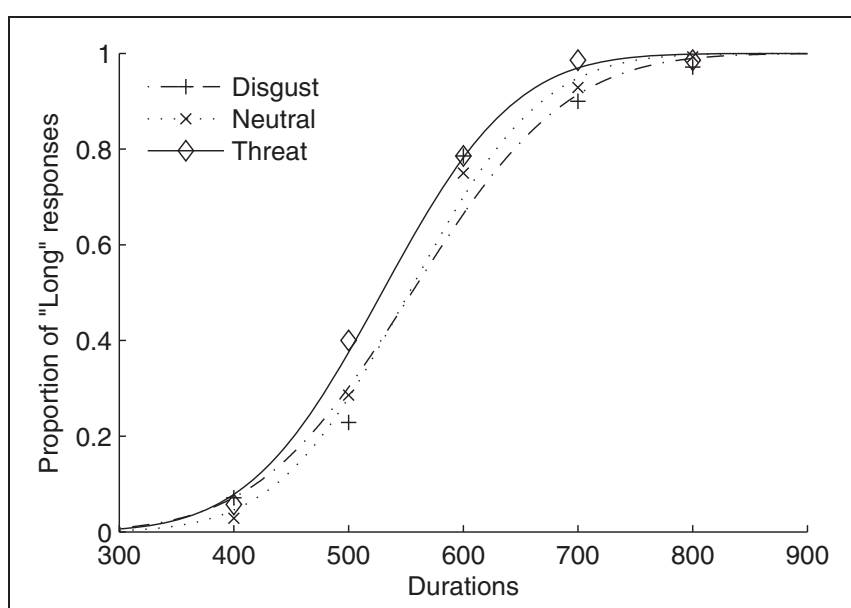

FIGURE 1 | Mean proportions of “Long" responses plotted against probe durations and fitted psychometric functions for three emotion conditions (neutral, threat, and disgust). The dotted curve and crosses represent the neutral condition, the dash-dotted curve and pluses the disgust condition, and the solid curve and diamonds the threat condition.

(Shi et al., 2008; Vroomen and Keetels, 2010). In addition, we measured the Weber fraction with the ratio of JND/TBP.

Figure 1 shows average psychometric curves for the three emotion (i.e., neutral, disgust, and threat) conditions in Experiment 1. The mean TBPs $( \pm S E)$ for the tactile $\mathrm{S} / \mathrm{L}$ duration pair $300 / 900 \mathrm{~ms}$ were $552 \pm 14,550 \pm 19$, and $529 \pm 15 \mathrm{~ms}$ for the neutral, disgust, and threat conditions, respectively (Figure 2A). A repeated-measures ANOVA showed that the type of emotion picture significantly influenced the (subsequently performed) judgment of tactile duration, $\left[F_{(2,26)}=4.41, p<0.05\right]$. Followon linear contrast tests revealed tactile TBP to be significantly lower in the threatening condition compared to both the neutral $(p<0.01)$ and disgust $(p=0.05)$ conditions, while there was no difference between the latter $(p>0.1)$. This pattern indicates that the modulatory influence of emotional pictures on tactile duration judgments was due mainly to the threatening condition. The lower TBP in this condition means that participants tended to overestimate the physical tactile duration of a vibratory stimulus preceded by a threatening picture. Interestingly, however, the subjective ratings of arousal (mean 7.41) were as high for disgusting pictures as for threatening pictures (mean 6.86). Given that duration overestimation only occurred in the threatening condition, arousal level alone cannot explain the crossmodal emotional modulation of time judgments.

The mean JNDs $( \pm$ SE) were $72 \pm 8,73 \pm 18$, and $59 \pm 12 \mathrm{~ms}$ for the neutral, disgust and threat conditions (Figure 2B). A oneway repeated-measures ANOVA on JNDs failed to reveal any difference among three types of emotion pictures, $\left[F_{(2,26)}=0.39\right.$, $p=0.68]$. The Weber fractions $( \pm \mathrm{SE})$ were $0.13 \pm 0.01,0.14 \pm$ 0.04 , and $0.11 \pm 0.02$ for the neutral, disgust, and threat conditions, respectively. A repeated-measures ANOVA also indicated no difference among three conditions, $\left[F_{(2,26)}=0.32, p=0.73\right]$. Both results suggested that emotional pictures did not influence the sensitivity of the subsequent tactile duration judgments.
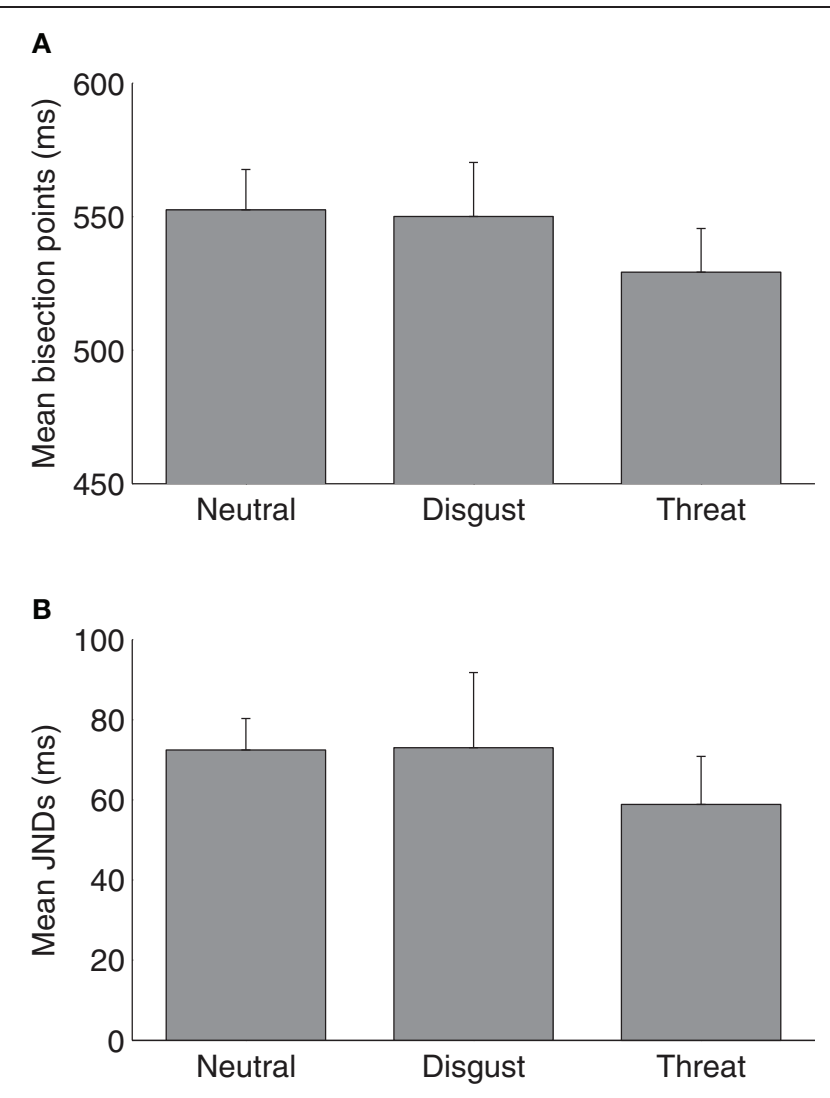

FIGURE 2 | (A) Mean temporal bisection points and (B) mean JNDs (and associated standard errors) for three emotional conditions $(n=14)$.

Experiment 2 was designed to examine how threatening pictures influence performance on short-range $(300 / 900 \mathrm{~ms})$ and long-range $(1000 / 1900 \mathrm{~ms})$ tactile temporal bisection tasks. In the short-range task, the mean TBPs $( \pm$ SE) were $550 \pm 12$ and $573 \pm 12 \mathrm{~ms}$ for the threat and neutral conditions, respectively, and in the long-range task, the points were $1399 \pm 16$ (threat) and $1385 \pm 18 \mathrm{~ms}$ (neutral), respectively (Figure 3A). A two-way repeated-measures ANOVA with the factors temporal bisection range (300/900 vs. $1000 / 1900 \mathrm{~ms})$ and emotional picture type (threat vs. neutral) revealed the main effect of temporal bisection range, $\left[F_{(1,14)}=2136.55, p<0.01\right]$, and the interaction, $\left[F_{(1,14)}=6.18, p<0.05\right]$, to be significant; the main effect of emotional picture type was non-significant, $\left[F_{(1,14)}=0.14, p=\right.$ 0.71]. Follow-up simple contrast tests showed that the TBP was lower with threatening pictures (indicative of a duration overestimation) in the short-range task, $\left[F_{(1,14)}=5.17, p<0.05\right]$, but not in the long-range task, $\left[F_{(1,14)}=0.71, p=0.42\right]$. Thus, while the results from the short-range condition are consistent with those of Experiment 1, there was no evidence of crossmodal duration lengthening in the long-range condition.

The mean JNDs $( \pm \mathrm{SE})$ were $55 \pm 12$ and $69 \pm 9 \mathrm{~ms}$ for the threat and neutral conditions in the short-range task, and $119 \pm 21$ and $152 \pm 12 \mathrm{~ms}$ for the threat and neutral conditions, respectively, in the long-range task (Figure 3B). A two-way repeated-measures ANOVA revealed that JND was larger in the 


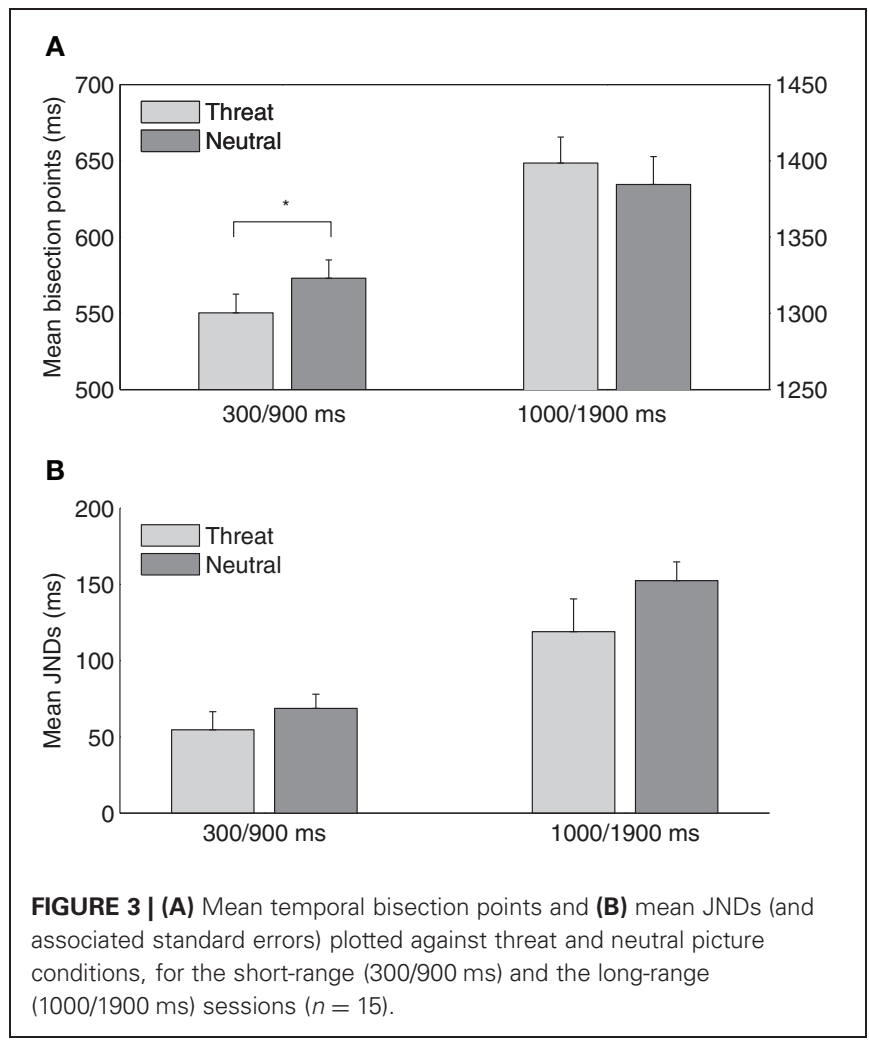

long- than the short-range task, $\left[F_{(1,14)}=32.61, p<0.01\right]$, and was marginally smaller in the threat than the neutral condition, $\left[F_{(1,14)}=4.54, p=0.05\right]$. This indicated that the threatening picture might increase the sensitivity of the temporal bisection for the subsequent tactile duration task. However, the interaction between the duration range and the emotion type was not significant, $\left[F_{(1,14)}=0.80, p=0.39\right]$. To compare task difficulties, we further calculated the Weber fractions. They were $0.10 \pm 0.02,0.12 \pm 0.02,0.09 \pm 0.01$, and $0.11 \pm 0.01$ for the threat and neutral conditions in the short- and longrange tasks, respectively. A repeated-measures ANOVA revealed non-significant main effects and interaction (duration range: $\left[F_{(1,14)}=0.58, p=0.46\right]$; emotion: $\left[F_{(1,14)}=3.62, p=0.08\right]$; interaction: $\left.\left[F_{(1,14)}=0.01, p=0.97\right]\right)$, which suggested task difficulties were relative similar among different conditions (e.g., the short- vs. long-range task).

However, it remains unclear from Experiment 2 whether the absence of a crossmodal duration overestimation following threatening pictures in the long-range temporal bisection task $(1000 / 1900 \mathrm{~ms})$ is due to the modulatory effect of emotion passively dissipating over time. Experiment 3 was designed to examine this question by comparing the effects of short (500 $\mathrm{ms})$ and long $(1500 \mathrm{~ms})$ ISIs between the emotional picture and the tactile stimulus using the short-range temporal bisection task $(300 / 900 \mathrm{~ms})$. The intervals from the onset of the emotional picture to the offset of the tactile stimulus in the long ISI condition were then similar to that in the longrange condition (Experiment 2). Figure 4A depicts the mean tactile TBPs for the neutral and threat picture conditions for short and long visual-tactile ISIs, respectively. The average TBPs

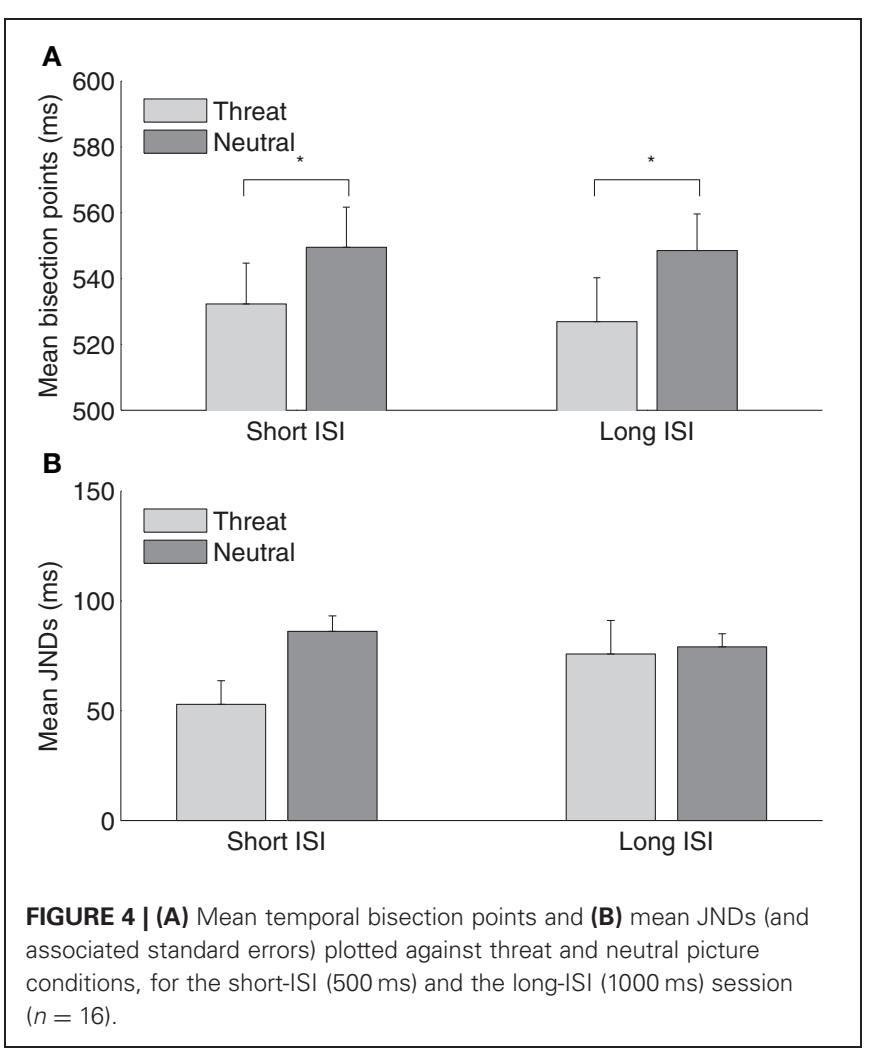

$( \pm$ SE) were $532 \pm 12$ and $549 \pm 11$ for threatening and neutral pictures in the short-ISI condition, and $527 \pm 12$ (threatening) and $549 \pm 10 \mathrm{~ms}$ (neutral) in the long-ISI condition. A two-way repeated-measures ANOVA with main terms of ISI and emotional picture type revealed the bisection points to be significantly lower in the threatening compared to the neutral condition, for both short and long visual-tactile ISIs. There were no effects involving ISI (main effect, $\left[F_{(1,15)}=0.26, p=0.62\right]$; interaction, $\left.\left[F_{(1,15)}=0.11, p=0.74\right]\right)$. This indicates that the modulatory effect of threatening picture in the short-range condition did not simply lessen over time, i.e., as a function of merely lengthening the ISI between the emotional picture and the tactile stimulus.

Figure 4B depicts the mean JNDs $( \pm S E)$ for the neutral and threat conditions in the short and long visual-tactile ISIs. A twoway repeated-measures ANOVA revealed that JNDs were not influenced by the visual-tactile ISI, $\left[F_{(1,15)}=0.58, p=0.46\right]$, but modulated by the type of pictures, $\left[F_{(1,15)}=4.91, p<0.05\right]$. However, there was no interaction between the visual-tactile ISI and the emotion picture, $\left[F_{(1,15)}=3.07, p=0.1\right]$. The significant smaller JNDs in the threat than the neutral condition confirmed the finding in Experiment 2. Both results suggest that threating pictures might increase the sensitivity of subsequent tactile temporal bisection task. Weber fractions were $0.10 \pm 0.02$, $0.16 \pm 0.01$ for the threat and neutral conditions in the short ISI and $0.15 \pm 0.03,0.15 \pm 0.01$ for the correspondent conditions in the long ISI. A repeated-measures ANOVA, however, showed no effects of the visual-tactile ISI, $\left[F_{(1,15)}=0.61, p=0.45\right]$, the type of pictures, $\left[F_{(1,15)}=3.19, p=0.10\right]$, and their interaction, $\left[F_{(1,15)}=2.48, p=0.14\right]$. 


\section{DISCUSSION}

The present study was designed to investigate the effect of viewing visual emotional stimuli on the subsequent estimation of the duration of non-emotional tactile events. We compared the effects of viewing three types of emotional pictures (neutral, threat, and disgust) in a short-range $(300 / 900 \mathrm{~ms})$ tactile temporal bisection task in Experiment 1. The results revealed the processing of threatening pictures to lengthen, relative to the neutral baseline, the subsequent judgments of tactile duration, as evidenced by a lowered mean TBP in the threat compared to the neutral condition. Interestingly, the lengthening effect was not simply due to the high-arousal induced by the threatening pictures: both threat and disgust pictures were rated as high in arousal negative in valence in the subjective ratings (using SAM sheets) of the participants in the present study as well as in the IAPS norms. Yet, no lengthening effect was evident in the disgust condition. This is clearly inconsistent with the predictions deriving from the assumption of a general arousal effect.

Previous studies of judged durations of emotional events themselves have shown that arousal and valences are two main factors for duration distortions (Angrilli et al., 1997; Droit-Volet et al., 2004; Noulhiane et al., 2007; Grommet et al., 2011). Using IAPS pictures, Angrilli and colleagues observed that the durations of high-arousal negative-valence pictures were overestimated (Angrilli et al., 1997). A similar effect has been reported for the auditory modality, with high-arousal negative sounds being judged as longer in duration than positive ones (Noulhiane et al., 2007). Moreover, a recent study suggests that negative higharousal activation, such as produced by a frightening movie, can also influence the subsequent time judgment of a neutral visual event (Droit-Volet et al., 2011). However, it is not clear from those studies whether arousal activation from one modality can influence time perception in another modality. In contrast to these earlier studies on the temporal perception of emotional events themselves, in the present study, we focused on duration distortions induced by crossmodal emotional linkages. We found that viewing a rather threatening (e.g., a snake attacking), but not a disgusting (e.g., a mutilated body), picture expanded the subsequent tactile duration, although both threat and disgust emotions induced high-arousal. Our findings suggest that the crossmodal modulatory effect of emotion depends on the type of emotional stimuli. This is consistent with the "discrete emotion" theory (Izard and Ackerman, 2000; Mikels et al., 2005), which posits that different core emotions (such as disgust, fear, anger, etc.) link different behavioral functions. Studies of the affective modulation of the startle blink reflex (Balaban and Taussig, 1994; Stanley and Knight, 2004) and duration estimation of emotional faces (Droit-Volet et al., 2007; Droit-Volet and Gil, 2009) suggest that the emotion of disgust has less salience than that of threat. A threatening picture often portrays an attack signal, which invokes the anticipation (or fear) of potential damage to perceiver's body. Thus, the perceiver is put in a state in which she/he needs to react as quickly as possible to the threatening signal (e.g., fight or flight). Indeed, it has been found that automatic defense systems come into operation within an "eye blink" for biologically relevant threat events (e.g., snakes, spiders), with their activation being based mainly on preattentive coding mechanisms (Öhman, 1997; Öhman and Mineka, 2001). The threatening event also establishes a strong association between the visual and tactile modalities, as suggested by several neuro-imaging studies (Dong et al., 1994; Gray and Tan, 2002; Keysers et al., 2004; Lloyd et al., 2006). For example, posterior parietal cortex has been shown to play an important role in the early integration of visual information with somatosensory, proprioceptive signals. Lloyd and colleagues found an increase in posterior parietal cortex activity in response to observing a sharp (painful) stimulus, vs. a nonpainful stimulus, touching a rubber hand in peripheral space, in the absence of any direct tactile stimulation (Lloyd et al., 2006). Consistent with reports such as these, our findings provide further behavioral evidence of visual-tactile associations elicited by threat-type emotional pictures.

The asymmetrical crossmodal modulation of duration judgments by pictures of threat versus those of disgust would also argue in favor of multiple clock models (Ivry and Richardson, 2002; Buhusi and Meck, 2005; Bueti, 2011). On this notion, time processing is "distributed" to different sensory-specific brain regions, with each of the multiple clocks operating separately. Within this framework, our results complement, rather than being in conflict with, previous, unimodal studies of emotional modulations of duration judgments. These studies have shown that the durations of emotional pictures themselves are overestimated, likely due to the "visual" clock being modulated by the pictures' arousal and valence signals. Our results go beyond this by showing that emotions induced via the visual modality may influence the "tactile" clock, depending on the strength of the emotional association induced between the visual and tactile modalities.

How does visual threat influence the tactile clock? Does exposure to threatening pictures subsequently speed up the tactile pacemaker or/and shorten the switch latency? Using a short- and a long-range temporal bisection task in Experiment 2, we observed a crossmodal duration lengthening by the threatening pictures in the short-range temporal bisection task $(300 / 900 \mathrm{~ms})$, replicating the finding of Experiment 1; by contrast, no such lengthening was observed in the long-range task (1000/1900 ms). The lacking crossmodal modulation in the long-range condition suggests that the tactile pacemaker is unlikely to be speeded up by preceding high-arousal visual stimuli. Otherwise, one would have expected to see a general slope effect, i.e., a larger duration expansion in the long-range condition. A recent study (Grommet et al., 2011) of the time estimation of visual fear cues using two different duration ranges $(250 / 1000 \mathrm{~ms}, 400 / 1600 \mathrm{~ms})$ concluded that the fear effects were mediated mainly by the switch latency, rather than the speeding up of the internal pacemaker. In the study of Grommet et al., the duration expansion of the fear cue itself was of a similar magnitude in both the short- and the long-range condition.

If the tactile switch latency is shortened by the presentation of threatening images in the present study, then why did we fail to observe a duration lengthening in the long-range condition? No difference on Weber fractions between the short- and long-range conditions suggests that the task difficulty cannot be the reason for the non-effect in the long-range condition. Furthermore, the mean standard errors of the TBPs were not significant different 
between the short and long duration conditions (12 vs $17 \mathrm{~ms}$, $p>0.1$ ). This could rule out the potential cause by large variations for long duration estimations. We suggest that the absence of such an effect is due to a dynamic shifting of attention from emotional activation to emotional regulation mechanisms (Zakay, 1989; Macar et al., 1994; Casini and Macar, 1997; Fortin, 2003). Emotional activation is often followed by emotional regulation, in line with the existence of two emotional pathways, one subcortical and one cortical (LeDoux, 1995). The former is rapidly activated by potentially dangerous or survival-relevant stimulieven though the stimuli are not fully processed, facilitating the preparation of (physiologically autonomous) response programs for avoidance (flight) or fight. The cortical pathway, by contrast, processes information more precisely, though this takes more time. Precise cortical stimulus analysis in turn can help to inhibit or correct "erroneous" early responses elicited by the subcortical pathway, thus readjusting the subsequent behavior. When participants in the present study are exposed to threatening pictures, attentional resources may first be rapidly directed to the defensive system, including the somatosensory system, for preparing a reaction. Possibly, the strong visual-tactile linkage reduces the latency of the tactile switch at the beginning. Consistent with this, tactile duration was overestimated in the short-range temporal bisection tasks of the present Experiments 1 and 2. While the same would apply to the long-range condition, participants (in this condition) would eventually realize that the tactile vibration is not a threat event. Accordingly, attentional resources would be increasingly redirected to processes of emotional regulation. As a consequence, some pulses may be lost in the time accumulation, leading to an underestimation of the tactile duration. The absence of an (overt) emotional modulation in the long-range condition may then arise from the overestimation brought about by the shortened switch latency being nulled by an underestimation owing to the emotional regulation.

It is interesting to note, however, in both short- and long-range conditions the sensitivity of temporal bisection task increased in the threat condition compared to the neutral condition. The higher sensitivity (smaller JND) in the threat condition is further confirmed in Experiment 3 and shown a trend in Experiment 1. These results may well reflect the general alerting effect induced by threatening pictures. However, the alerting could not account for the differential effects in the short- and long-range conditions.

One alternative explanation: general emotional attenuation, might account for the absence of duration lengthening in the

\section{REFERENCES}

Angrilli, A., Cherubini, P., Pavese, A., and Mantredini, S. (1997). The influence of affective factors on time perception. Percept. Psychophys. 59, 972-982.

Balaban, M. T., and Taussig, H. N. (1994). Salience of fear/threat in the affective modulation of the human startle blink. Biol. Psychol. 38, 117-131.

Bradley, M. M., Codispoti, M., Cuthbert, B. N., and Lang, P. J. (2001). Emotion and motivation I:

long-range condition. As reported in previous unimodal studies (Angrilli et al., 1997; Noulhiane et al., 2007), the duration lengthening induced by emotional stimuli disappeared for the judgment of long durations (usually above $4 \mathrm{~s}$ ). The absence of an emotion effect in these studies has been attributed to dynamic pacemaker changes by emotional attenuation: the pacemaker rate would be increased by the onset of the emotion event and would then gradually return to baseline when emotion attenuates over time. Note, however, that the emotional attenuation could also be the result of emotional regulation - which are the two faces of one and the same coin.

One interesting question, though, is at what point in time emotional regulation takes over. The results of the present Experiment 3 suggest that emotional regulation is unlikely to occur prior to the subsequent (tactile) event. Recall that in the long-ISI condition of Experiment 3, the time interval from the onset of the emotional picture to the offset of the tactile vibration was the same as that in the long duration condition of Experiment 2. If emotional regulation (or emotional attenuation) took place immediately after the onset of the emotional event, one would predict both conditions to yield the same crossmodal emotional modulation of duration judgments. However, on the opposite (and unlike the nulling effect in the long duration condition), the tactile duration lengthening effect evoked by threatening pictures was almost as large in the long-ISI as in the short-ISI condition. This suggests that the crossmodal linkage activated by threatening events was not attenuated before the subsequent event, at least within the time rage of our study $(3 \mathrm{~s})$. The defensive system appears to be still highly activated and dominant for reacting to the external world after the threatening events. Only when the subsequent event is identified to be non-threatening (as under the long duration condition of Experiment 2) does emotional regulation become dominant and the emotion-induced defensive bias dissipates gradually.

In summary, the present results indicate that the crossmodal subjective-duration lengthening effect is emotion-specific: tactile duration is overestimated following exposure to pictures of threat, but not to pictures of disgust of the same high-arousal potential. However, the duration lengthening disappears for longrange durations. This pattern may be best explained by the latency of the tactile (clock's) switch being shortened by crossmodal emotional activation, while emotional regulation takes over after the subsequent (tactile) event is identified as a non-threatening signal.

Bueti, D., Bahrami, B., and Walsh, V. (2008). Sensory and association cortex in time perception. J. Cogn. Neurosci. 20, 1054-1062.

Buhusi, C. V., and Meck, W. H. (2005). What makes us tick? Functional and neural mechanisms of interval timing. Nat. Rev. Neurosci. 6, 755-765.

Casini, L., and Macar, F. (1997). Effects of attention manipulation on judgments of duration and of intensity in the visual modality. Mem. Cognit. $25,812-818$.
Chen, K. M., and Yeh, S. L. (2009). Asymmetric cross-modal effects in time perception. Acta Psychol. (Amst.) 130, 225-234.

Chen, L., Shi, Z., and Müller, H. J. (2010). Influences of intraand crossmodal grouping on visual and tactile ternus apparent motion. Brain Res. 1354, 152-162.

Chen, L., Shi, Z., and Müller, H. J. (2011). Interaction of perceptual grouping and crossmodal temporal capture in tactile apparent-motion. 
PLoS ONE 6:e17130. doi: 10.1371/ journal.pone.0017130

Dong, W. K., Chudler, E. H., Sugiyama, K., Roberts, V. J., and Hayashi, T. (1994). Somatosensory, multisensory, and task-related neurons in cortical area $7 \mathrm{~b}(\mathrm{PF})$ of unanesthetized monkeys. J. Neurophysiol. 72, 542-564.

Droit-Volet, S., Brunot, S., and Niedenthal, P. M. (2004). Perception of the duration of emotional events. Cogn. Emotion 18, 849-858.

Droit-Volet, S., Fayolle, S. L., and Gil, S. (2011). Emotion and time perception: effects of film-induced mood. Front. Integr. Neurosci. 5, 1-9.

Droit-Volet, S., and Gil, S. (2009). The time - emotion paradox. Philos. Trans. R. Soc. Lond. B Biol. Sci. 364, 1943-1953.

Droit-Volet, S., and Meck, W. H. (2007). How emotions colour our perception of time. Trends Cogn. Sci. $11,504-513$

Droit-Volet, S., Meck, W. H., and Penney, T. B. (2007). Sensory modality and time perception in children and adults. Behav. Processes $74,244-250$

Effron, D. A, Niedenthal, P. M., Gil, S., and Droit-Volet, S. (2006). Embodied temporal perception of emotion. Emotion 6, 1-9.

Fortin, C. (2003). "Attentional timesharing in interval timing," in Functional and Neural Mechanisms of Interval Timing, ed W. H. Meck (London, UK: CRC Press), 235-260.

Ghose, G. M., and Maunsell, J. H. (2002). Attentional modulation in visual cortex depends on task timing. Nature 419, 616-620.

Gibbon, J., Church, R. M., and Meck, W. H. (1984). Scalar timing in memory. Ann. N.Y. Acad. Sci. 423, 52-77.

Gray, R., and Tan, H. Z. (2002). Dynamic and predictive links between touch and vision. Exp. Brain Res. 145, 50-55.

Grommet, E. K., Droit-Volet, S., Gil, S., Hemmes, N. S., Baker, A. H., and Brown, B. L. (2011). Time estimation of fear cues in human observers. Behav. Processes 86, 88-93.

Hare, R. D. (1963). The estimation of short temporal intervals terminated by shock. J. Clin. Psychol. 19, 378-380.
Ivry, R. B., and Richardson, T. C. (2002). Temporal control and coordination: the multiple timer model. Brain Cogn. 48, 117-132.

Izard, C. E., and Ackerman, B. P. (2000). "Motivational, organizational, and regulatory functions of discrete emotions," in Handbook of Emotions, Vol. 2, eds M. Lewis and J. M. Haviland-Jones (New York, NY: The Guilford Press), 253-264.

Keysers, C., Wicker, B., Gazzola, V., Anton, J. L., Fogassi, L., and Gallese, V. (2004). A touching sight: SII/PV activation during the observation and experience of touch. Neuron 42 335-346.

Lang, P. J., Bradley, M. M., and Cuthbert, B. N. (2005). International Affective Picture System (IAPS): Affective Ratings of Pictures and Instruction Manual. Emotion. Gainesville, FL: NIMH, Center for the Study of Emotion and Attention.

Lang, P. J., Wapner, S., and Werner, H. (1961). The effect of danger upon the experience of time. Am. J. Psychol. 74, 94-97.

LeDoux, J. E. (1995). Emotion: clues from the brain. Annu. Rev. Psychol. $46,209-235$.

Lloyd, D., Morrison, I., and Roberts, N. (2006). Role for human posterior parietal cortex in visual processing of aversive objects in peripersonal space. J. Neurophysiol. 95, 205-214.

Macar, F., Grondin, S., and Casini, L. (1994). Controlled attention sharing influences time estimation. Mem. Cognit. 22, 673-686.

Matell, M., and Meck, W. H. (2004). Cortico-striatal circuits and interval timing: coincidence detection of oscillatory processes. Cogn. Brain Res. 21, 139-170.

Mikels, J. A., Fredrickson, B. L., Larkin, G. R., Lindberg, C. M., Maglio, S. J., and Reuter-Lorenz, P. A. (2005). Emotional category data on images from the international affective picture system. Behav. Res. Methods 37, 626-630.

Noulhiane, M., Mella, N., Samson, S., Ragot, R., and Pouthas, V. (2007). How emotional auditory stimuli modulate time perception. Emotion 7, 697-704.

Öhman, A. (1997). "As fast as the blink of an eye: evolutionary preparedness for preattentive processing of threat," in Attention and Orienting: Sensory and Motivational Processes, eds P. J. Lang, R. F. Simons, and M. T. Balaban (Mahwah, NJ: Lawrence Erlbaum Associates), 165-184.

Öhman, A., and Mineka, S. (2001) Fears, phobias, and preparedness: toward an evolved module of fear and fear learning. Psychol. Rev. 108 483-522.

Penney, T. B., Gibbon, J., and Meck, W. H. (2000). Differential effects of auditory and visual signals on clock speed and temporal memory. J. Exp. Psychol. Hum. Percept. Perform. 26, 1770.

Phelps, E. A., and LeDoux, J. E. (2005). Contributions of the amygdala to emotion processing: from animal models to human behavior. Neuron 48, 175-187.

Poliakoff, E., Miles, E., Li, X., and Blanchette, I. (2007). The effect of visual threat on spatial attention to touch. Cognition 102, 405-414.

Rozin, P., and Fallon, A. E. (1987). A perspective on disgust. Psychol. Rev. 94, 23-41.

Shi, Z., Chen, L., and Müller, H. J. (2010). Auditory temporal modulation of the visual ternus effect: the influence of time interval. Exp. Brain Res. 203, 723-735.

Shi, Z., Hirche, S., Schneider, W. X., and Müller, H. J. (2008). Influence of visuomotor action on visual-haptic simultaneous perception: a psychophysical study. 2008 Symposium on Haptic Interfaces for Virtual Environment and Teleoperator Systems. IEEE, 65-70.

Stanley, J., and Knight, R. G. (2004). Emotional specificity of startle potentiation during the early stages of picture viewing. Psychophysiology 41, 935-940.

Treisman, M. (1963). Temporal discrimination and the indifference interval: implications for a model of the "internal clock." Psychol. Monogr. 77, 1-31.

Treutwein, B., and Strasburger, $\mathrm{H}$ (1999). Fitting the psychometric function. Percept. Psychophys. 61, 87-106.

van Wassenhove, V., Buonomano, D. V., Shimojo, S., and Shams, L. (2008). Distortions of subjective time perception within and across senses. PLoS ONE 3:e1437. doi 10.1371/journal.pone.0001437

Vroomen, J., and Keetels, M. (2010). Perception of intersensory synchrony: a tutorial review. Atten Percept. Psychophys. 72, 871-884.

Walker, J. T., and Scott, K. J. (1981). Auditory-visual conflicts in the perceived duration of lights, tones and gaps. J. Exp. Psychol. Hum. Percept. Perform. 7, 1327-1339.

Wearden, J. H. (1992). Temporal generalization in humans. J. Exp. Psychol. Anim. Behav. Process. 18, 134-144.

Wearden, J. H. (2006). When do auditory visual differences in duration judgments occur? Q. J. Exp. Psychol. 59, 1709-1724.

Wearden, J. H., Edwards, H., Fakhri, M., and Percival, A. (1998). Why "sounds are judged longer than lights": application of a model of the internal clock in humans. Q. J. Exp. Psychol. B 51, 97-120.

Zakay, D. (1989). "Subjective time and attentional resource allocation: an integrated model of time estimation," Time and Human Cognition: A Life-Span Perspective, Vol. 59, eds I. Levin and D. Zakay. (Amsterdam: Elsevier), 365-397.

Zakay, D., and Block, R. A. (1996). The role of attention in time estimation processes. Adv. Psychol. 115, 143-164.

Conflict of Interest Statement: The authors declare that the research was conducted in the absence of any commercial or financial relationships that could be construed as a potential conflict of interest.

Received: 08 February 2012; accepted: 07 May 2012; published online: 23 May 2012.

Citation: Shi Z, Jia L and Mueller HJ (2012) Modulation of tactile duration judgments by emotional pictures. Front. Integr. Neurosci. 6:24. doi: 10.3389/fnint. 2012.00024

Copyright (๑) 2012 Shi, Jia and Mueller. This is an open-access article distributed under the terms of the Creative Commons Attribution Non Commercial License, which permits non-commercial use, distribution, and reproduction in other forums, provided the original authors and source are credited. 


\section{APPENDIX}

Table A1 | IAPS stimuli used in the current study.

\begin{tabular}{|c|c|c|}
\hline Category of pictures & IAPS number & Picture description \\
\hline \multirow[t]{5}{*}{ Mutilation pictures } & 3030 & Mutilation \\
\hline & 3053 & Burn victim \\
\hline & 3060 & Mutilation \\
\hline & 3071 & Mutilation \\
\hline & 3120 & Dead body \\
\hline \multirow[t]{10}{*}{ Animal or human attacking pictures } & 1052 & Snake \\
\hline & 1120 & Snake \\
\hline & 1201 & Spider \\
\hline & 1300 & Pit bull \\
\hline & 1321 & Bear \\
\hline & 1930 & Shark \\
\hline & 6250 & Aimed gun \\
\hline & 6260 & Aimed gun \\
\hline & 6300 & Knife \\
\hline & 6510 & Attack \\
\hline \multirow[t]{19}{*}{ Neutral pictures } & 2840 & Chess \\
\hline & 5500 & Mush room \\
\hline & 7000 & Rolling pin \\
\hline & 7009 & Mug \\
\hline & 7035 & Mug \\
\hline & 7041 & Baskets \\
\hline & 7050 & Hair driver \\
\hline & 7059 & Key ring \\
\hline & 7090 & Book \\
\hline & 7140 & Bus \\
\hline & 7150 & Umbrella \\
\hline & 7161 & Pole \\
\hline & 7185 & Abstract art \\
\hline & 7224 & File cabinets \\
\hline & 7233 & Plate \\
\hline & 7235 & Chair \\
\hline & 7490 & Window \\
\hline & 7700 & Office \\
\hline & 7705 & Cabinet \\
\hline
\end{tabular}

